\title{
Comparative Analysis of Mechanical Behavior of Unconventional Natural Fibers and their Union Fabrics
}

\author{
Behera BK $^{1 *}$, Kavita ${ }^{2}$ and Lalit Jajpura ${ }^{2}$ \\ ${ }^{1}$ Department of Textile Technology, Indian Institute of Technology, India \\ ${ }^{2}$ Department of Fashion Technology, BPS Mahila Vishwavidyalaya, India
}

Submission: October 14, 2019; Published: November 04, 2019

*Corresponding author: Behera BK, Department of Textile Technology, Indian Institute of Technology, New Delhi, India

\section{Abstract}

In the view of sustainability, an attempt has been made to explore the possibilities of producing high-quality apparel fabric from selected unconventional natural fibers such as Banana, Hemp, Linen, and Ramie. A comparative study was made on the mechanical behavior of these fiber fabrics and their respective union fabrics with cotton. The mechanical properties investigated

Keywords: Mechanical properties; Banana; Hemp; Linen; Ramie; union fabric

\section{Introduction}

In recent years, consumers are becoming much more conscious of their choices than ever before. They have begun showing an increased interest in environmentally friendly materials and processes. This trend results in encouragement of production and use of fibers from renewable sources as a substitute for conventional fibers like petroleum-based synthetic fibers and even cotton. Because of sustainability, cotton is also not favorable as it requires lots of water and pesticides for cultivation. The shortage of land also favors the food crop cultivation rather than cotton. Moreover, climatic conditions are not conducive for cotton cultivation in many countries although the cotton fabric is being used all over the world irrespective of weather conditions. Therefore, the global textile industry is in continuous search of 'unconventional and alternate natural fibers which could be obtained either as by-product (Banana, Pina, Sugarcane etc.) or grown on sub-secondary land (Hemp, Ramie, Flax, Sisal, Kenaf etc.) with less or almost no use of pesticides and chemicals and need substantially less water compared to cotton [1]. India, being a tropical country, is very rich with a large number of vegetable fibers such as sisal, pineapple, kenaf, jute, hemp, ramie, flax, banana, bamboo, and coir, etc. which are mostly of long-staple length and considerable stiffness. Some of these fibers are neglected and many of them are completely unexplored as regard to their textile potential in both the apparel and industrial sector.
While developing such new fiber-mix, the individual fiber characteristics substantially influence the primary attributes of the resulting fabric and hence the fabric properties and performance [2-6]. Therefore, in this research, efforts are being made to explore the possibilities of producing high-quality apparel fabric from selected unconventional natural fibers such as Banana, Hemp, Linen and Ramie [7, 8]. A comparative study is made on the mechanical behavior of these fibers and their respective union fabrics with cotton.

\section{Materials and methods}

\section{Materials}

For this research four unconventional natural fibers such as Banana, Hemp, Linen, and Ramie are used to produce union fabric with Cotton as a reference sample. Yarn samples of $30 \mathrm{Ne}$ were developed from all above five different fibers in industry and used for fabric development under identical conditions.

\section{Methods}

Fabric sample development: The following nine grey fabric samples were prepared in a weaving mill under controlled manufacturing conditions using construction parameters to produce fabric areal density approximately around $145 \mathrm{~g} / \mathrm{m}^{2}$ as given in [Table 1]. 


\section{Current Trends in Fashion Technology \& Textile Engineering}

Table 1: Constructional parameters of fabric samples.

\begin{tabular}{|c|c|c|c|c|c|c|c|}
\hline Sample code & Fabric sample & Warp type & Weft type & Ends per inch & Picks per inch & Weave & Weight $\left(\mathrm{g} / \mathrm{m}^{2}\right)$ \\
\hline $\mathrm{C}$ & $100 \%$ Cotton & $100 \%$ Cotton & $100 \%$ Cotton & 80 & 76 & Plain & 143 \\
\hline B & 100\% Banana & 100\% Banana & 100\% Banana & 30 & 50 & Plain & 153 \\
\hline $\mathrm{H}$ & 100\% Hemp & $100 \%$ Hemp & $100 \%$ Hemp & 60 & 54 & Plain & 136 \\
\hline $\mathrm{L}$ & 100\% Linen & 100\% Linen & 100\% Linen & 30 & 30 & Plain & 141 \\
\hline $\mathrm{R}$ & 100\% Ramie & $100 \%$ Ramie & 100\% Ramie & 46 & 60 & Plain & 135 \\
\hline СВ & $\begin{array}{l}\text { Cotton-Banana } \\
\text { Union Fabric }\end{array}$ & $100 \%$ Cotton & $100 \%$ Banana & 72 & 60 & Plain & 150 \\
\hline $\mathrm{CH}$ & $\begin{array}{c}\text { Cotton-Hemp Union } \\
\text { Fabric }\end{array}$ & $100 \%$ Cotton & $100 \%$ Hemp & 75 & 60 & Plain & 137 \\
\hline CL & $\begin{array}{c}\text { Cotton-Linen Union } \\
\text { Fabric }\end{array}$ & $100 \%$ Cotton & 100\% Linen & 90 & 76 & Plain & 155 \\
\hline CR & $\begin{array}{c}\text { Cotton-Ramie Union } \\
\text { Fabric }\end{array}$ & $100 \%$ Cotton & $100 \%$ Ramie & 90 & 76 & Plain & 144 \\
\hline
\end{tabular}

Chemical processing of fabrics: The chemical pretreatment of all the fabrics was carried out in industry maintaining standard parameters used in commercial production of cotton fabric. The

sequence of chemical processing of fabrics done is as follows in [Figure 1].

$$
\begin{aligned}
& \text { Hot wash } \\
& \stackrel{\downarrow}{\downarrow} \\
& \text { (Hydrochloric acid-5gpl, wetting agent-2gpl, } \\
& \text { sequestering agent- } 2 \mathrm{gpl} \text {, temp- } 70^{\circ} \mathrm{c} \text {, time-30 min) } \\
& \downarrow \\
& \text { Hot wash } \\
& \downarrow \\
& \text { (Caustic soda-10gpl, wetting agent-2gpl, non-ionic } \\
& \text { detergent-2gpl, soda- } 2 \mathrm{gpl} \text {, temp- } 95^{\circ} \mathrm{c} \text {, time- } 60 \mathrm{~min} \text { ) } \\
& \downarrow \\
& \text { Bleaching } \\
& \text { (Hydrogen Peroxide-5gpl, Soda-2gpl, temp-90 }{ }^{\circ} \mathrm{c} \text {, } \\
& \text { time-30 } \mathrm{min} \text { ) } \\
& \downarrow \\
& \text { Hot wash } \\
& \text { Cold } \\
& \text { d wash } \\
& \downarrow \\
& \text { Neutralization } \\
& \text { Hot wash } \\
& \text { Cold wash with acetic acid } \\
& \downarrow \\
& \text { Stentering } \\
& \text { (Drying at } 160^{\circ} \mathrm{c} \text {, speed }-40 \mathrm{~m} / \mathrm{min} \text { ) } \\
& \downarrow \\
& \text { Calendering } \\
& \text { ( } 8 \mathrm{~kg} \text { pressure, temp- } 60^{\circ} \mathrm{c} \text {, speed-30m/min) } \\
& \stackrel{\downarrow}{\downarrow}
\end{aligned}
$$

Figure 1: Sequence of chemical processing of fabrics.

Fiber surface morphology: Scanning electron microscopic is used to assess the surface morphology of fibers at the micron and submicron level. The samples were coated with gold using an ion sputter and examined using EVO, 18 ZEISS scanning electron microscopes operating at an accelerating voltage of $20 \mathrm{kV}$.

Tensile testing of fibers: The tensile test of fibers was carried out on Instron tensile tester 4302 as per ASTM D
3822-01 to determine properties like tenacity, initial modulus, extensibility, etc. The average of 50 specimens was taken.

I. Yarn Structure: The fiber arrangement on yarn surface was observed by EVO, 18 ZEISS scanning electron microscopes operating at an accelerating voltage of $20 \mathrm{kV}$. The samples were coated with gold using an ion sputter and examined at magnification levels of 500 . 
II. Yarn count: Count of the yarns was evaluated by a gravimetric method using the digital weighing balance.

III. Yarn twist: The Twist of the single yarns was measured by a '10inch Twist Contraction Method'. For the twist calculation of 2 ply yarn, 'Statex Auto Twist Tester V2.13' was used. An average of 10 observations was taken for each sample.

IV. Tensile properties of Yarn: The tensile properties of yarn were measured on Instron Tensile Tester 4302 as per ASTM D 2256-02. An average of 25 specimens was taken.

\section{Fabric testing}

Fabric dimensional properties: Fabric dimensional properties such as thread density, areal density, and thickness

Table 2: Fabric dimensional parameters. were measured. Fabric thread density was calculated by counting number of yarns per inch in warp and weft directions using a pick glass. The areal density of the fabric samples was evaluated as per IS 1964-2001 method. A circular sample of $11.3 \mathrm{~cm}$ diameter was cut using a round cutter and then weighed on electronic balance to calculate GSM. Fabric thickness values were measured on thickness tester under $20 \mathrm{gf} / \mathrm{cm}^{2}$ pressure and an average of 5 readings was taken. All these dimensional properties are given in Table 2. As expected, the fabrics with high thread density or coarse warp \& weft yarns exhibit high areal density. The fabric samples containing Hemp and Ramie are comparatively thinner and lighter. Linen fabric has the least cover factor due to the lesser number of yarns per unit length. Next in the sequence is banana fabric.

\begin{tabular}{|c|c|c|c|c|c|c|c|c|c|c|c|}
\hline $\begin{array}{c}\text { Sample } \\
\text { code }\end{array}$ & Fabric sample & $\begin{array}{c}\text { Warp } \\
\text { count (Ne) }\end{array}$ & $\begin{array}{c}\text { Weft count } \\
\text { (Ne) }\end{array}$ & $\begin{array}{c}\text { Ends per } \\
\text { inch }\end{array}$ & $\begin{array}{c}\text { Picks per } \\
\text { inch }\end{array}$ & Weave & $\begin{array}{c}\text { Thickness } \\
\text { (mm) }\end{array}$ & \multicolumn{2}{|c|}{$\begin{array}{c}\text { Weight (g/ } \\
\text { m2) }\end{array}$} & \multicolumn{2}{|c|}{ Cover Factor } \\
\hline Warp & Weft & Mean \\
\hline B & $100 \%$ Cotton & $2 / 60$ & 30 & 80 & 76 & Plain & 0.24 & 143 & 14.61 & 13.87 & 21.24 \\
\hline H & $100 \%$ Banana & $2 / 20$ & 20 & 30 & 50 & Plain & 0.35 & 153 & 9.49 & 11.18 & 16.88 \\
\hline L & $100 \%$ Hemp & 21 & 21 & 60 & 54 & Plain & 0.19 & 136 & 13.09 & 11.78 & 19.36 \\
\hline R & $100 \%$ Linen & 21 & 21 & 30 & 30 & Plain & 0.28 & 141 & 9.26 & 9.26 & 15.45 \\
\hline CB & $\begin{array}{c}\text { Cotton-Banana } \\
\text { Union Fabric }\end{array}$ & $2 / 60$ & 20 & 72 & 60 & Plain & 0.25 & 150 & 13.15 & 13.42 & 20.27 \\
\hline CH & $\begin{array}{c}\text { Cotton-Hemp } \\
\text { Union Fabric }\end{array}$ & $2 / 60$ & 21 & 75 & 60 & Plain & 0.20 & 137 & 13.69 & 13.09 & 20.37 \\
\hline CL & $\begin{array}{c}\text { Cotton-Linen } \\
\text { Union Fabric }\end{array}$ & $2 / 60$ & 21 & 90 & 76 & Plain & 0.22 & 155 & 16.43 & 16.58 & 23.27 \\
\hline CR & $\begin{array}{c}\text { Cotton-Ramie } \\
\text { Union Fabric }\end{array}$ & $2 / 60$ & 28 & 90 & 76 & Plain & 0.22 & 144 & 16.43 & 14.36 & 22.36 \\
\hline
\end{tabular}

Tensile properties of Fabric: The tensile test of fabric samples was carried out on Instron tensile tester as per ASTM D 5035 - 06. The test specifications are as given below:

Gauge length $=75 \mathrm{~mm}$, Speed $=300 \mathrm{~mm} / \mathrm{min}$

No of specimen tested $=5$ each for warp and weft directions

Fabric Stiffness: The fabric stiffness was determined using Cantilever test method as per ASTM D 1388-96 standard. Five specimens of size $25 \mathrm{~cm} \times 2.5 \mathrm{~cm}$ were cut in warp and weft wise direction each. For each specimen, 4 readings were recorded by taking the two ends and the two faces of the fabric. The bending length for each testing direction was calculated to the nearest $1 \mathrm{~mm}$, using the following equation:

$\mathrm{C}=0 / 2$

Where:

$\mathrm{C}=$ bending length in $\mathrm{cm}$

$\mathrm{O}=$ length of overhang in $\mathrm{mm}$.

Abrasion resistance: Abrasion resistance of the fabrics was determined by Martindale Abrasion Tester under IS12673:189.
Five observations from each fabric sample were cut and subjected to abrasion with standard abradant. The samples were visually analyzed for any fiber rupture due to abrasion at the end of 15000 revolutions.

Tear Strength: Tearing strength of the fabric samples was determined by using Elmendorf tearing tester under ASTM D2261 test method. From each fabric five samples were cut in the warp direction and five in the weft direction. An average of warp and weft samples reading was taken.

\section{Results and Discussion}

\section{Fiber surface morphology}

TheSEMimages ofall five fibers attwo differentmagnifications are shown in Figure 2. The well-known convolutions in the shape of curls are visible in cotton fibers whereas the banana fiber has a straight rigid structure with striations on surface. There are striations, crevices and narrower ravines on the surface of hemp and linen fibers, whereas there are few or none on the surface of ramie fiber. The appearance of ramie is much clean and smooth. Linen fiber shows pithy material deposition on its surface. It is quite evident from these microscopic figures that 


\section{Current Trends in Fashion Technology \& Textile Engineering}

surface anatomy of all these fibers is different even though they are all cellulosic. The difference in surface morphology of these fibers results in the difference in their inter fiber friction during mechanical processing and hence spinnability of these fibers is quite different leading to variation in yarn and fabric properties.
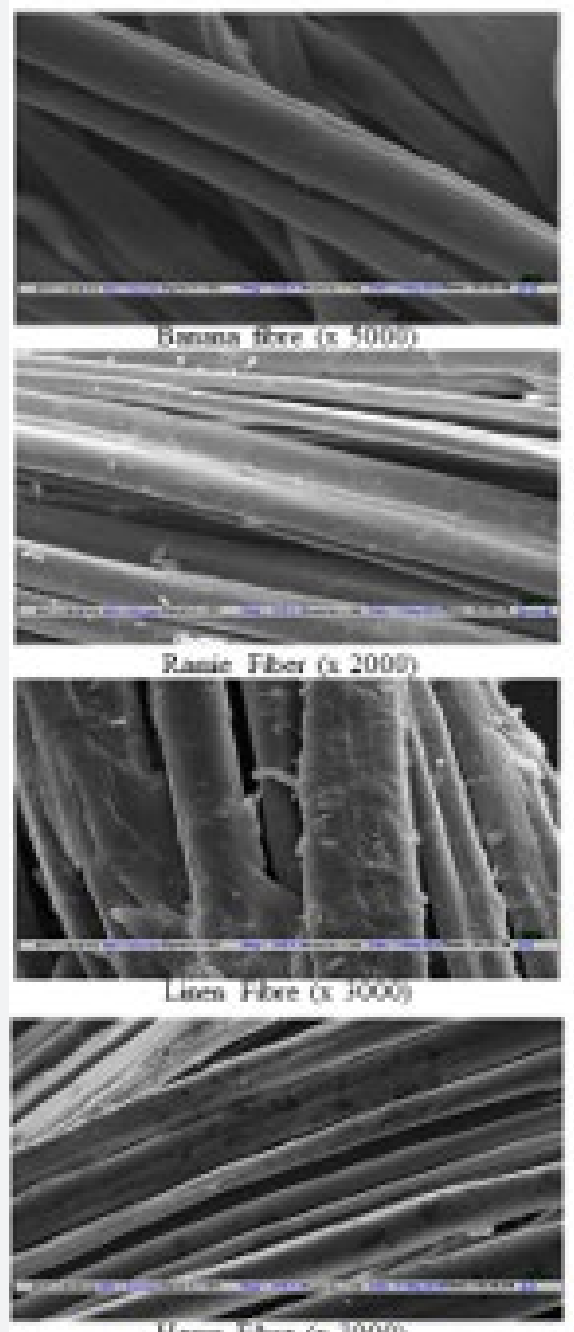

Hene the (ix 3000)

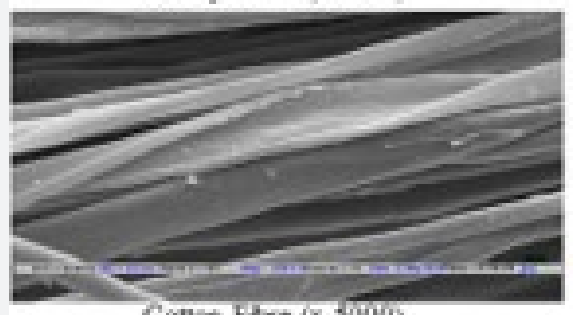

Consa Fixe $(x) \widehat{000})$
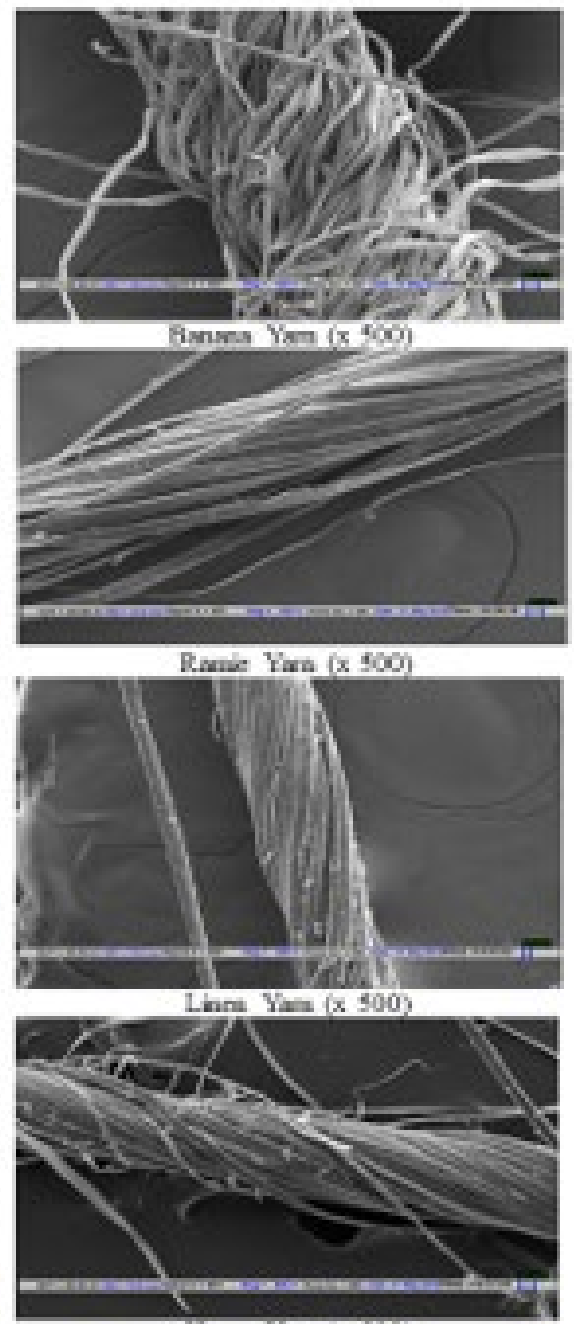

Heap Van $(x, 900)$

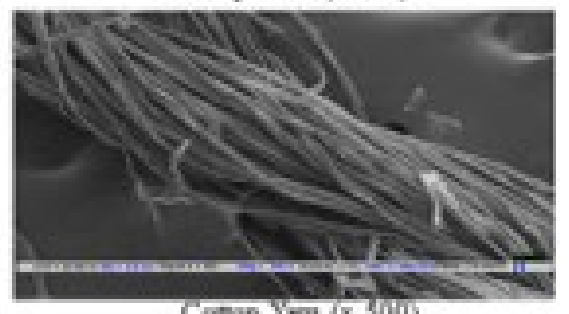

Comin yem (x 200)

Figure 2: SEM images of different fibers.

\section{Fiber properties}

Fiber properties are studied to understand their role in yarn and fabric mechanical properties. The results are given in Table 3. It may be observed from the table that ramie is the strongest among all the natural fibers, followed by linen, hemp, cotton, and banana fiber. Linen is also least extensible, whereas cotton is highly extensible among all the fibers. The results suggest that ramie, linen, and hemp can be used as durable fabric, cotton contributes maximum to mechanical comfort due to its 
extensibility, whereas banana fiber exhibits the least advantage towards mechanical properties of the fabric mainly because of

its coarseness which makes the fiber stiffer, brittle and least flexible.

Table 3: Fiber properties.

\begin{tabular}{|c|c|c|c|c|c|}
\hline Fiber type & Banana & Hemp & Linen & Ramie & Cotton \\
\hline Fineness (denier) & 27 & 18.7 & 14.1 & 7.4 & 1.8 \\
\hline Tenacity (g/den) & 3.34 & 4.45 & 5.80 & 6.19 & 3.85 \\
\hline Extensibility (\%) & 2.8 & 2.3 & 2.1 & 2.8 & 3 \\
\hline
\end{tabular}

\section{Yarn properties}

The results for various yarn properties are shown in Table 4. It is evident that hemp and linen yarns give the highest tenacity values followed by cotton, ramie, and banana. The banana yarn gives the maximum extensibility values followed by cotton yarn.

Table 4: Yarn properties.
All bast fiber yarns give almost the same and very low values of extensibility. It may be mentioned that it is difficult to correlate fiber strength with yarn strength of various natural fibers as the length variation and fiber extent in yarn structure are different for each fiber type.

\begin{tabular}{|c|c|c|c|c|c|c|c|c|}
\hline Fiber type & Yarn type & Denier & $\begin{array}{c}\text { Yarn Diameter } \\
\text { (mm) }\end{array}$ & $\begin{array}{c}\text { Tenacity at max } \\
\text { load (CN/Tex) }\end{array}$ & $\begin{array}{c}\text { Strain at } \\
\text { max load } \\
\text { (\%) }\end{array}$ & $\begin{array}{c}\text { Modulus } \\
\text { (CN/Tex) }\end{array}$ & $\begin{array}{c}\text { Twist direc- } \\
\text { tion }\end{array}$ & $\begin{array}{c}\text { Twist per } \\
\text { inch }\end{array}$ \\
\hline Banana & Single & 265.75 & 0.21 & 7.29 & 6.53 & 127.08 & $\mathrm{Z}$ & 24.56 \\
\hline Hemp & Single & 250.23 & 0.2 & 26.46 & 1.91 & 185.86 & $\mathrm{Z}$ & 9.55 \\
\hline Linen & Single & 250.09 & 0.14 & 26.68 & 1.96 & 722.1 & $\mathrm{Z}$ & 10.77 \\
\hline Ramie & Single & 189.8 & 0.14 & 16.085 & 1.95 & 950.34 & $\mathrm{Z}$ & 14.24 \\
\hline Cotton & 2 ply & 177 & 0.15 & 16.21 & 5.17 & 403.98 & $\mathrm{Z}$ & 12.20 \\
\hline
\end{tabular}

\section{Fabric properties}

Fabric dimensional properties: Fabric dimensional properties are given in Table 5 . The results show that fabrics with high thread density or coarse warp \& weft yarns exhibit high areal density. The fabric samples containing Hemp and Ramie are comparatively thinner and lighter. Linen fabric has the least cover factor due to the lesser number of yarns per unit length. Next in the sequence is banana fabric.

Table 5: Fabric dimensional parameters.

\begin{tabular}{|c|c|c|c|c|c|c|c|c|c|c|c|}
\hline \multirow{2}{*}{$\begin{array}{l}\text { Sample } \\
\text { code }\end{array}$} & \multirow{2}{*}{ Fabric sample } & \multirow{2}{*}{$\begin{array}{c}\text { Warp } \\
\text { count(Ne) }\end{array}$} & \multirow{2}{*}{$\begin{array}{l}\text { Weft count } \\
\text { (Ne) }\end{array}$} & \multirow{2}{*}{$\begin{array}{l}\text { Ends per } \\
\text { inch }\end{array}$} & \multirow{2}{*}{$\begin{array}{l}\text { Picks per } \\
\text { inch }\end{array}$} & \multirow{2}{*}{ Weave } & \multirow{2}{*}{$\begin{array}{c}\text { Thickness } \\
\text { (mm) }\end{array}$} & \multirow{2}{*}{$\begin{array}{l}\text { Weight } \\
\left(\mathrm{g} / \mathrm{m}^{2}\right)\end{array}$} & \multicolumn{3}{|c|}{ Cover Factor } \\
\hline & & & & & & & & & Warp & Weft & Mean \\
\hline $\mathrm{C}$ & $100 \%$ Cotton & $2 / 60$ & 30 & 80 & 76 & Plain & 0.24 & 143 & 14.61 & 13.87 & 21.24 \\
\hline B & 100\% Banana & $2 / 20$ & 20 & 30 & 50 & Plain & 0.35 & 153 & 9.49 & 11.18 & 16.88 \\
\hline $\mathrm{H}$ & 100\% Hemp & 21 & 21 & 60 & 54 & Plain & 0.19 & 136 & 13.09 & 11.78 & 19.36 \\
\hline $\mathrm{L}$ & 100\% Linen & 21 & 21 & 30 & 30 & Plain & 0.28 & 141 & 9.26 & 9.26 & 15.45 \\
\hline $\mathrm{R}$ & 100\% Ramie & $2 / 28$ & 28 & 46 & 60 & Plain & 0.21 & 135 & 12.29 & 11.33 & 18.64 \\
\hline $\mathrm{CB}$ & Cotton-Banana Union Fabric & $2 / 60$ & 20 & 72 & 60 & Plain & 0.25 & 150 & 13.15 & 13.42 & 20.27 \\
\hline $\mathrm{CH}$ & Cotton-Hemp Union Fabric & $2 / 60$ & 21 & 75 & 60 & Plain & 0.20 & 137 & 13.69 & 13.09 & 20.37 \\
\hline $\mathrm{CL}$ & Cotton-Linen Union Fabric & $2 / 60$ & 21 & 90 & 76 & Plain & 0.22 & 155 & 16.43 & 16.58 & 23.27 \\
\hline $\mathrm{CR}$ & Cotton-Ramie Union Fabric & $2 / 60$ & 28 & 90 & 76 & Plain & 0.22 & 144 & 16.43 & 14.36 & 22.36 \\
\hline
\end{tabular}

Tensile behavior of fabrics: The results of the tensile properties of fabric samples are shown in Table 6. For warp direction, the $100 \%$ Hemp fabric shows the highest values of breaking loads while 100\% Banana shows the least. Linen and Ramie exhibit similar breaking loads but higher than Cotton. All union fabrics except Cotton-banana (in warp direction) give higher breaking strength than their respective pure fabrics. Also, cotton-hemp and cotton-linen show higher values of loads in the weft direction. The results in Table 5 show that all pure fabrics have higher extensibility in weft direction than warp direction. $100 \%$ banana shows the highest extensibility. The least values of extensibility are shown by $100 \%$ linen and $100 \%$ ramie. This influence can also be seen in union fabric of cotton and linen, where weft wise extensibility is lower than warp wise because of linen yarn in the weft direction. 
Fabric stiffness: The results for bending properties are shown in Table 6. It may be seen from the results that $100 \%$ banana shows the lowest bending stiffness. On the other hand, $100 \%$-linen fabric gives the highest bending rigidity. The reason for the high bending rigidity of linen fabric is the coarse linen fibers, whose diameter is much higher; this, in turn, increases the stiffness. Also, all the union fabrics give a higher value of warp bending length than $100 \%$ cotton. Weft bending length values are higher for union fabrics as compared to respective pure fabrics.
Tearing strength: The results of tearing behavior of fabric samples are given in Table 6. All bast fiber fabrics e.g. linen hemp and ramie show values of tearing strength on the higher side followed by banana and cotton. This can be attributed to the higher yarn strength of these fibers. Moreover, linen fabric has a loose structure, in which the grouping of threads occurs, resulting in higher tear strength. In the case of union fabrics, the warp wise tearing strength is almost the same to $100 \%$ cotton due to the presence of same yarn i.e. cotton. Also, the union fabrics containing bast fibers exhibit higher tearing strength in the weft direction.

Table 6: Fabric mechanical properties.

\begin{tabular}{|c|c|c|c|c|c|c|c|c|}
\hline \multirow{2}{*}{ Sample code } & \multicolumn{2}{|c|}{ Tensile strength (N) } & \multicolumn{2}{|c|}{ Elongation (\%) } & \multicolumn{2}{|c|}{ Bending Length (cm) } & \multicolumn{2}{|c|}{ Tearing strength (N) } \\
\hline & Warp & Weft & Warp & Weft & Warp & Weft & Warp & Weft \\
\hline $\mathrm{C}$ & 655.8 & 356.4 & 7.82 & 19.61 & 3.3 & 2.1 & 15 & 13 \\
\hline B & 329 & 263 & 8.28 & 29.18 & 2.9 & 2 & 23 & 15.6 \\
\hline $\mathrm{H}$ & 1015 & 704.2 & 8.13 & 15.06 & 3.9 & 2.8 & 35.5 & 33.6 \\
\hline $\mathrm{L}$ & 790.2 & 670.6 & 5.17 & 16.75 & 4.3 & 2.9 & Fail & Fail \\
\hline $\mathrm{R}$ & 796.25 & 392.42 & 5.92 & 15.07 & 4.1 & 2.6 & 35.3 & 15.8 \\
\hline $\mathrm{CB}$ & 559.6 & 330.16 & 13.26 & 19.17 & 2.6 & 2.2 & 18.4 & 11.2 \\
\hline $\mathrm{CH}$ & 654.4 & 850 & 9.08 & 16.1 & 2.8 & 3.1 & 16.6 & 29 \\
\hline CL & 796.5 & 816.8 & 11.03 & 9.69 & 2.6 & 3.4 & 19.3 & 58 \\
\hline CR & 812.8 & 572.8 & 12.21 & 11.14 & 3.1 & 3.1 & 15.5 & 33 \\
\hline
\end{tabular}

Abrasion resistance: All the samples were tested to observe the resistance of the fabric surface against the breaking of threads due to the no. of revolutions of the abradant. The outcomes are reported in Table 7 . All the samples have a very good resistance against abrasion and show no thread breakage even after 15000 revolutions which reveal that these natural fibers and their union fabrics are equally good as compared to cotton concerning abrasion resistance.

Table 7: Results of abrasion test.

\begin{tabular}{|c|c|c|c|c|c|c|c|c|c|}
\hline Sample code & C & B & H & $\mathbf{L}$ & $\mathbf{R}$ & CB & CH & CL & CR \\
\hline Abrasion after 15000 rev. & Pass & Pass & Pass & Pass & Pass & Pass & Pass & Pass & Pass \\
\hline
\end{tabular}

\section{Conclusion}

SEM analysis reveals that surface morphology of allnatural cellulosic fibers is quite different even though they are all cellulosic. Tensile strength of ramie is highest, and linen exhibits the least extensibility. Linen fabric shows the highest bending rigidity among all-natural fibers due to large fiber diameter. Fabrics made from bast fibers exhibit high tearing strength compared to other natural fiber-based fabrics. Abrasion resistance of all-natural fiber fabrics is reasonably good.

\section{References}

1. Mwaikambo LY (2006) Review of the History, Properties and Application of Plant Fibres. African J of Sci \& Tech 7(2): 120-133.

2. Fan J, Hunter L (2009) Engineering apparel fabrics and garments. In: $1^{\text {st }}(\mathrm{edn}) .$, The Textile Institute, Woodhead Publishing in Textiles, India.

3. Behera BK, Mishra R (2007) Effect of crease behavior, drape and formability on appearance of light weight worsted suiting fabrics. Ind. J of Fib. \& Text. Res (32): 319-325.
4. Tohidi SD, Jeddi AAA, Nosrati H (2013) Analyzing of the woven fabric Geometry on the Bending Rigidity Properties. Intl. J of Text. Sci 2(4): 73-80.

5. Hue J, Chan Y (1998) Effect of fabric mechanical properties on drape. Text Res J 68(10): 57-64.

6. Khan MMR, Chen Y, Belsham T, Laugue C, Landry H, et al. (2011) Fineness and tensile properties of hemp fibres. Biosystems Engineering 108: 9-17.

7. Li J, Feng J, Zhang H, Zhang J (2010) Wear properties of Hemp, Remie and Linen Fabrics after Liquid Ammonia/Crosslinking Treatment. FIBRES \& TEXTILES in Eastern Europe 18(82): 81-85.

8. Jang YY, Kim JJ (2009) Analysis of physical/Mechanical properties and color of Bast fibre fabrics dyed using Rubia akane Nakai. J of Fashion Business 13(3): 86-98. 
Your next submission with Juniper Publishers will reach you the below assets

- Quality Editorial service

- Swift Peer Review

- Reprints availability

- E-prints Service

- Manuscript Podcast for convenient understanding

- Global attainment for your research

- Manuscript accessibility in different formats ( Pdf, E-pub, Full Text, Audio)

- Unceasing customer service

Track the below URL for one-step submission https://juniperpublishers.com/online-submission.php 